\title{
The Determination of Single and Mixture Toxicity at High Concentrations of Some Acidic Pharmaceuticals via Aliivibrio fischeri
}

\author{
Ayșe Handan Dökmeci • Ismet Dökmeci • Hilmi Ibar
}

Received: 2 November 2013 / Accepted: 15 December 2013 / Published online: 8 May 2014

(C) Springer International Publishing Switzerland 2014

\begin{abstract}
Pharmaceutical and Personal Care Products (PPCPs) may cause serious and significant environmental pollution. Environmental analyses have detected pharmaceuticals in addition to conventional chemical pollutants. In our study, the acute toxicity of ibuprofen, naproxen, diclofenac, salicylic acid and substances that are mixtures themselves (INDS) on Alivibrio fischeri bacterium were assessed with the use of ToxAlert ${ }^{\circledR}$. The selected materials are acidic in nature, highly polarized and widely sold over-the-counter analgesics. Doseresponse curves were drawn, and linear regression analyses and probit analyses determined their $50 \%$-effective concentrations $\left(\mathrm{EC}_{50}\right)$. The pharmaceuticals alone are unlikely to have acute impacts in aquatic environments. However, when evaluated in combination with A. fischeri bacterium, the acute toxicity of the INDS mixture was $\mathrm{EC}_{50} 7.09 \pm 5.1 \mathrm{mg} / \mathrm{L}$ and the acute toxicity of TUs was 14.10 , which indicates their very toxic quality for organisms. Since the target components do not exist in isolation, we should primarily consider the toxicity of the mixture only at high concentrations.
\end{abstract}

Keywords Ibuprofen $\cdot$ Naproxen $\cdot$ Diclofenac $\cdot$ Salicylic acid $\cdot$ Mixture toxicity Alivibrio fischeri

\section{Introduction}

What happens to drugs after being used? Are they completely used up by our bodies, or are they partially disposed via excretion? Where do unused and stored drugs end up? Do drugs

\footnotetext{
A. H. Dökmeci $(\bowtie)$

Emergency and Disaster Management Department, Namik Kemal University, School of Health, 59030 Çorlu, Tekirdag, Turkey

e-mail: hdokmeci@nku.edu.tr

I. Dökmeci

Department of Pharmacology, Trakya University, Faculty of Medicine, Edirne, Turkey e-mail: idokmeci@trakya.edu.tr

H. Ibar

Department of Chemistry, Trakya University, Faculty of Science, Edirne, Turkey e-mail: hibar@trakya.edu.tr
} 
affect other organisms in the environment? Pharmaceutical and Personal Care Products (PPCPs) are ubiquitous, and raise serious and significant problem of continuous and repetitive environmental pollution (Daughton and Ternes 1999). As a result of the marketing of new medicines and personal care products and their detection in the aquatic environment, the effects of PPCPs, in combination with other chemicals, has become a very pertinent topic. Although the concentrations of the medicines in the environment are very low (ng/L or ppt), as they remain part of a mixture, they may reduce or cancel the effect of each other (antagonistic effect) or they may increase the effect of one another (synergistic effect). The synergistic effects of medicines may create a potential risk to non-targeted organisms.

Recent studies have shown that very little is known about the long-term impacts of drugs on aquatic organisms when biological goals are considered. The same is also true for the impacts of compounds that are able to exist as mixtures. An important reason for the interest in medical substances in the environment is their purpose of creating biological effects. Drugs are lipophilic in order to penetrate cell membranes, and they can be hydrolyzed in the acidic $\mathrm{pH}$ of the stomach. They are persistent, and have high mobility in the liquid phase. Due to these characteristics, drug-active substances or metabolites can be bio-accumulated and cause effects both in aquatic and terrestrial ecosystems (Ternes et al. 1998; Fatta et al. 2007).

Although drugs are designed to target specific metabolic or molecular pathways in humans and animals, the majority of them have significant side effects. They may have toxic effects in various forms such as narcosis, polar narcosis, apnea, acetylcholinesterase inhibition, membrane irritation, or paralysis of the central nerve system (McCarty and MacKay 1993).

Drug residues do not exist as polluters solely in aquatic environments - they generally exist as compounds. Therefore, we need to scientifically assess the risks of those complex compounds to aquatic organisms as well as the organisms' level of exposure to them. Ecotoxicological studies have been conducted for more than two decades, to determine the combined effects and risks of various substances (Altenburger et al. 2000; Backhaus et al. 2000; Faust et al. 2001). Generally, there are two different concepts to estimate the toxicity of a mixture: (1) Total concentration; and (2) Independent impact.

The concentrations of individual compounds in a mixture will potentially have a higher combined effect if they comply with the concept of "the total concentration of compounds". Another significant point in the concept of total concentration, is its contribution to the total impact of the mixture even in applications that are below individually unobserved (neutral) concentrations of the substance. The activity form of this type of compound is known as narcosis. The potential of a chemical to cause narcosis depends on its hydrophobic state, and is widely defined as a "n-octanol water allocation quotient" $\left(\log K_{\text {ow }}\right)$ (Cleuvers 2003). Compounds defined as $\log K_{o w}>3$ have a relatively high capacity for bioaccumulation in the organism's tissues (Sanderson et al. 2003).

The increasing and widespread use of eco-toxicity tests have started to gain similar importance to chemical analyses in the control of water pollution. Such tests generally use prokaryotic and eukaryotic organisms. Of these, plants, algae, bacteria and shelled organisms are widely used in toxicity tests (Radix et al. 2000; Castillo et al. 2001; Cleuvers 2004; Schnell et al. 2009; Dietrich et al. 2010). In our study, sea bacteria (A. fischeri) was used as a test organism in a bioluminescene inhibition test. More recently, bio-tests with bioluminescence bacteria have been the focus of increased interest, because, although toxicity mechanisms differ greatly, any substance that has a toxic effect on one organism is noted to have a similar effect on others. Thus, the identification of luminescence inhibition is representative of the impact of a substance on more complex organisms (Ren and Frymier 2002; Parvez et al. 2006). The standard bioluminescence inhibition test is done in accordance with either ISO 
11348-3 or DIN 38412 L34 standards. Inhibitions of $A$. fischeri bacterium after exposure to various diluted solutions are calculated from their $\mathrm{EC}_{50}$ rates using probit and linear regression analysis.

The purpose of this study is to assess the single substance and combined toxicities present in high concentrations of naproxen, diclofenac, ibuprofen and salicylic acid (acetyl salicylic acid metabolite) via $A$. fischeri.

\section{Materials and Methods}

\subsection{Toxicity Testing of Pharmaceuticals}

Ibuprofen, diclofenac, naproxen, salicylic acid, $\mathrm{NaOH}, \mathrm{HCl}$ and $\mathrm{NaCl}$ were all purchased from Sigma-Aldrich (Merck, Darmstadt, Germany; purity $>98 \%$ ). We studied the single substance and mixture toxicity of naproxen, ibuprofen, diclofenac and salicylic acid using a long-term bioluminescence inhibition test with the marine bacterium A. fischeri acting as the test organism according to the protocol of the International Standard Organization (ISO 11348-3 1998). Samples of $100 \mathrm{mg} / \mathrm{L}$ were prepared from naproxen, ibuprofen, diclofenac, salicylic acid and the INDS mixture. Due to the low solubility of the drugs in water, stock solutions were prepared in $1 \%$ ethanol/water, which have a non-effective solubility for luminescence bacteria. It is recommended to carry out toxicity tests at $\mathrm{pH}$ 6-8 with a sodium chlorine solution of $20 \%$ or higher salinity (Onorati and Mecozzi 2003). Therefore, using $1 \mathrm{~N} \mathrm{NaOH}$ and $0.1 \mathrm{~N} \mathrm{HCl}$, the $\mathrm{pH}$ value of each stock solution was adjusted to the range $6-8$, the optimum interval for the organism. In order to provide the relevant osmotic pressure for test organisms, the salinity concentration of the stock solution was adjusted by $2 \%$ for $\mathrm{NaCl}$. Measurements were performed using Merck ToxAlert ${ }^{\circledR} 100$ kits. The prepared stock solutions were diluted at $80 \%, 50 \%, 25 \%, 12.5 \%, 6.75 \%, 3.2 \%$ and $0.8 \%$. Reactivation solutions at room temperature were mixed well, and were left for a minimum of 15 min after adding $12.5 \mathrm{~mL}$ reactivation solutions to the vial. The experiments used $A$. fischeri bacteria that were liquid dried and frozen at $-20^{\circ} \mathrm{C}$. Samples of $0.5 \mathrm{~mL}$ were transferred from the reactivation solution in the equipment's reservoir to the liquid dried bacteria; they were then gently agitated and allowed to stand for $15 \mathrm{~min}$. The bacteria and the diluted solutions were made ready for the tests. All tests were performed in duplicate. Data evaluation was performed according to ISO 11348-3 (Eq. 1), which resulted from the contrast of nontoxic free control samples within a 30minute exposure duration and the concentration-effect curves were analyzed as described below.

Bioluminescence inhibition:

$$
\%=1-\left[1-\left(\text { light intensity }_{\text {sample }_{\text {le }}} / \text { light intensity }_{\text {control }}\right] \times 100\right.
$$

Effective concentration $\left(\mathrm{EC}_{50}\right)$ was defined as the sample concentration that resulted in a $50 \%$ reduction in luminescence. The $\mathrm{EC}_{50}$ rates of samples were measured through the curve that represented the dilatation factor of the inhibition percentage rates of samples (ASTMD 1996). Following assessment of $\mathrm{EC}_{50}$ rates, the Toxic Unit (TU) dosage was determined. The Toxic Unit for Standard Material was calculated with reference to Sprague and Ramsay's (1965) formula: $(\mathrm{TUs})=\left(\mathrm{EC}_{50}\right)^{-1} \times 100$. Regarding this scale: if $\mathrm{TU}=0$, the sample is non-toxic (nt); if $\mathrm{TU}<1$, it is slightly toxic (st); if TU is $1-10$, it is classified as toxic (t); if TU is $11-100$, the sample is very toxic (vt) and if $\mathrm{TU}>100$, then the sample is extremely toxic (et). 


\section{Results}

A toxicity-unit (TU) scale was used to assess the toxicity of the tested samples. A doseresponse chart was drawn for ibuprofen, naproxen, diclofenac, salicylic acid and INDS, as shown in Fig. 1, and $\mathrm{EC}_{50}$ rates were found.

Regression equations and probit analyses were used to determine the Toxic Unit (TUs) for $\mathrm{EC}_{50}$ rates. According to the regression results, the $\mathrm{EC}_{50}$ rates were found to be $39.93 \pm 2.2,47.07 \pm 1.45,16.31 \pm 0.72,52.64 \pm 2.35$ and $5.13 \pm 8.1 \mathrm{mg} / \mathrm{L}$ for ibuprofen, naproxen, diclofenac, salicylic acid and INDS, respectively, compared with the TU rates of $2.50,2.03,6.10,1.89$ and 19.49, respectively. Probit analysis indicated that $\mathrm{EC}_{50}$ was $39.00 \pm 0.8,53.35 \pm 7.9,11.79 \pm 1.75,54.39 \pm 8.9$ and $7.09 \pm 5.1 \mathrm{mg} / \mathrm{L}$, respectively, while TU rates were $2.56,1.87,8.48,1.83$ and 14.10 , respectively (Table 1).

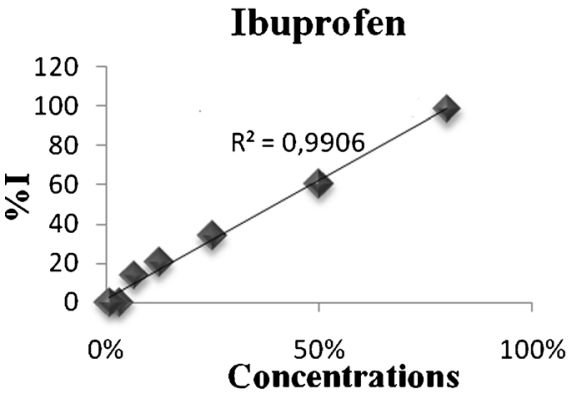

Diclofenac

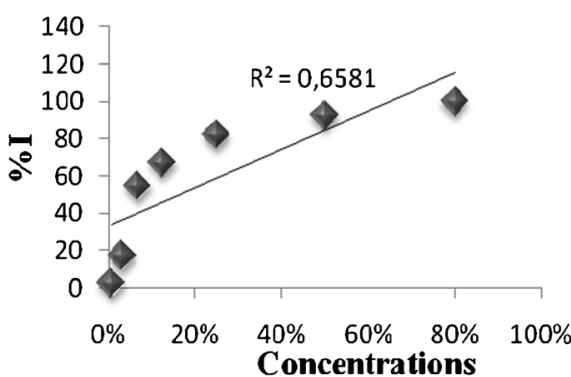

Concentrations
Naproxen

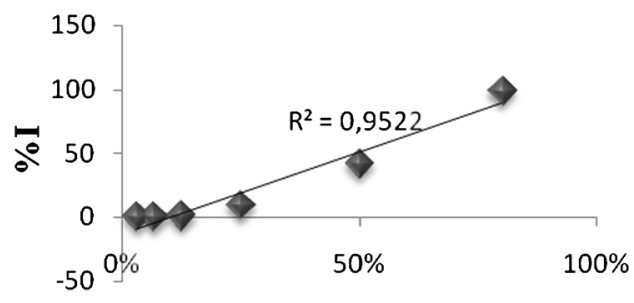

Concentrations

Salicylic acid

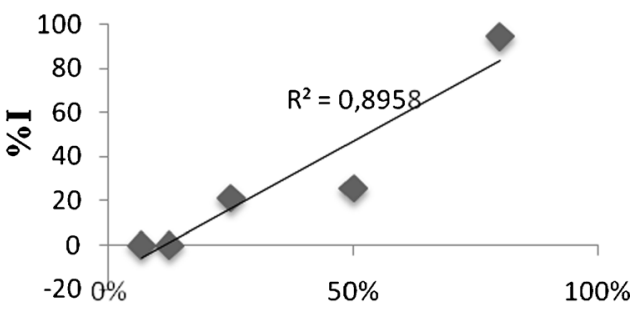

Concentrations

\section{INDS}

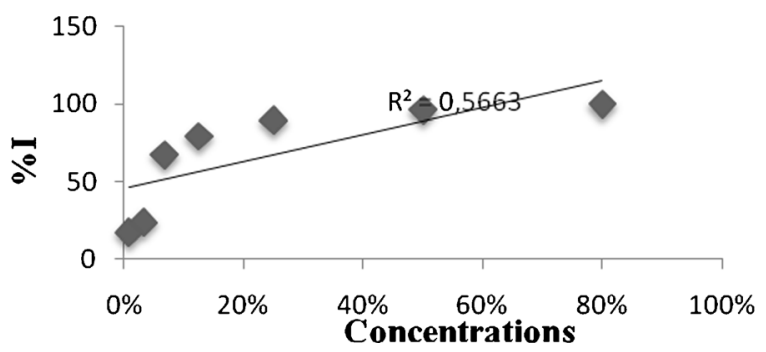

Fig. 1 Bioluminescence inhibition (\%) for tested compounds ToxAlert $100^{\circledR}$ 
Table $1 \mathrm{EC}_{50}$ and $\mathrm{TU}$ rates of drug components after regression and probit analyses

\begin{tabular}{llllll}
\hline Drug components & $\mathrm{EC}_{50}(\mathrm{mg} / \mathrm{L})$ (Regression analysis) & $\mathrm{TUs}$ & $\mathrm{EC}_{50}(\mathrm{mg} / \mathrm{L})$ (Probit analysis) & $\mathrm{TUs}$ & Log $\mathrm{K}_{\mathrm{ow}}$ \\
\hline $\mathrm{IBU}$ & $39.93 \pm 2.2$ & 2.5 & $39 \pm 0.8$ & 2.56 & 3.5 \\
NAP & $47.07 \pm 1.45$ & 2.03 & $53.35 \pm 7.9$ & 1.87 & 3.3 \\
DIC & $16.31 \pm 0.72$ & 6.1 & $11.79 \pm 1.75$ & 8.48 & 4.4 \\
SA & $52.64 \pm 2.35$ & 1.89 & $54.39 \pm 8.9$ & 1.83 & 2.3 \\
INDS & $5.13 \pm 8.1$ & 19.49 & $7.09 \pm 5.1$ & 14.10 & -
\end{tabular}

There was no significant difference between the TU rates obtained from those two analyses. The toxicity assessment showed that individual components were toxic, whereas the mixture was categorized as highly toxic.

In a bioluminescence inhibition test using A. fischeri for ibuprofen, Farré et al. (2001) reported that $\mathrm{EC}_{50}$ rates were 12.1 and $19.1 \mathrm{mg} / \mathrm{L}$, while Jin Sung Ra et al. (2008) found it to be $37.5 \mathrm{mg} / \mathrm{L}$. In our study, probit analysis determined $\mathrm{EC}_{50}$ to be $39 \pm 0.8 \mathrm{mg} / \mathrm{L}$, which is equivalent to a toxic TU rating for the organism.

In a bioluminescence inhibition test using $A$. fischeri for diclofenac, Ferrari et al. (2003) stated that $\mathrm{EC}_{50}$ was $11.45 \mathrm{mg} / \mathrm{L}$ and diclofenac compound was very sensitive in $A$. fischeri compared with other organisms. Farré et al. (2001) reported that $\mathrm{EC}_{50}$ rates for diclofenac were 13.3 and $13.7 \mathrm{mg} / \mathrm{L}$, whereas Ra et al. (2008) found $\mathrm{EC}_{50}$ to be $9.7 \mathrm{mg} / \mathrm{L}$. In our study, probit analysis determined $\mathrm{EC}_{50}$ to be $11.79 \pm 1.75 \mathrm{mg} / \mathrm{L}$, which is classified as being toxic for organisms. Compared with other target components, the most toxic is diclofenac.

In bioluminescence inhibition test using A. fischeri for salicylic acid, Farré et al. (2001) found $\mathrm{EC}_{50}$ to be $41.3 \mathrm{mg} / \mathrm{L}$, whereas Henschel et al. (1997) noted it to be $90 \mathrm{mg} / \mathrm{L}$. In another study, the lowest $\mathrm{EC}_{50}$ rate of salicylic acid was reported as $37 \mathrm{mg} / \mathrm{L}$, while the highest concentration in the aqueous environment was $60 \mu \mathrm{g} / \mathrm{L}$ (Karl et al. 2005). In our study, probit analysis results confirmed that $\mathrm{EC}_{50}$ was $54.39 \pm 8.9 \mathrm{mg} / \mathrm{L}$, which is classified as toxic for organisms.

In a bioluminescence inhibition test using $A$. fischeri for naproxen, Farré et al. (2001) confirmed $\mathrm{EC}_{50}$ to be 21.2 and $35.6 \mathrm{mg} / \mathrm{L}$. In our study, probit analysis determined $\mathrm{EC}_{50}$ to be $53.35 \pm 7.9 \mathrm{mg} / \mathrm{L}$, which is classified as toxic for organisms.

\section{Discussion}

Many studies have been performed on the acute toxic effects of medicines on non-targeted organisms, and the effects of medicines in isolation and in mixtures have been compared. According to the research results, the toxic effects of medicine mixtures are more complex and unpredictable compared to the toxic effects of single medicine (Dietrich et al. 2010; Flaherty and Dodson 2005; Cleuvers 2003, 2004). Dietrich et al. (2010) stated that Daphnia magna exposed to karbamazepine, diclofenac, $17 \alpha$-ethinylestradiol and metoprolol, did not experience a stronger effect when these medicines were applied as a mixture rather than individually. In contrast to this study, Cleuver $(2003,2004)$ examined the ecotoxic potentials of antiinflammatory drugs in addition to their various activities in different biotest groups with various aquatic organisms. The NSAID mixture (diclofenac, ibuprofen, naproxen, acetylsalicylic acid) was analyzed in acute Daphnia and algae tests. Although one sole compound either had no effect or only a slight effect, the mixture was determined to be toxic. Schnell et al. (2009) showed that the toxic effect of various therapeutic medicine mixtures is 
more significant than previously estimated on the liver cells of rainbow trout due to the synergistic effects of the compound. Lang and Kohidai (2012) stated that medicines $\left(\mathrm{EC}_{50}\right.$ $26.56 \pm 2.56 \mathrm{mg} / \mathrm{L}$ for DIC, $\mathrm{EC}_{50} 46.79 \pm 1.78 \mathrm{mg} / \mathrm{L}$ for IBU) do not have a potential acute toxic effect on Tetrahymena pyriformis although they are individually present in high concentrations. They reported that IBU and DIC components at the lowest concentration $(0.25 \mathrm{TU}$ diclofenac $+0.25 \mathrm{TU}$ ibuprofen) show additive effects when they are together, while they showed antagonistic effect in higher concentrations. Reasons for the inconsistent results in their study are that they used different species (Zhang et al. 2010) and different medicines interacting in the same or the opposite direction (Dietrich et al. 2010; Cleuvers 2004) Therefore, the existing studies on mixture toxicity should be expanded upon.

Annual consumption of ibuprofen is estimated to be in hundreds of tonnes (Koutsouba et al. 2003). Many studies have reported that ibuprofen is representative of anti-rheumatic medications (Wiegel et al. 2004). Studies have shown that $14 \%$ of consumed ibuprofen does not undergo change (Daughton and Ternes 1999). Almost every water sample taken within Europe is reported to have detectable levels of this active substance, because it is very frequently prescribed and its use is pervasive (Andreozzi et al. 2003; Rodriguez et al. 2003). Less than $1 \%$ of the diclofenac compound is excreted from the body. Its half-life $t_{1 / 2}$ is $4 \mathrm{~h}$. Entering the aqueous environment, it is decomposed rapidly by photodegradation in less than $24 \mathrm{~h}$ (Buser et al. 1998; Ayscough et al. 2000). Despite these characteristics, diclofenac has been specified as a very significant active drug component, both in surface waters and wastewater samples during long-term monitoring studies (Heberer 2002). Acetylsalicylic acid is used as an analgesic and anti-inflammatory, and is one of the most widely used pharmaceuticals. By 2000, sales had reached 1000 tonnes per annum in Europe (Heberer 2002; Dietrich et al. 2002). Its rate of use in the UK is 18 tonnes per annum (Jones et al. 2002). In a study conducted in Turkey, salicylic acid was detected at $18.74 \pm 3.3 \mathrm{ng} / \mathrm{L}$ in surface waters (Dökmeci et al. 2013). Naproxen is an over-the-counter anti-inflammatory drug that is

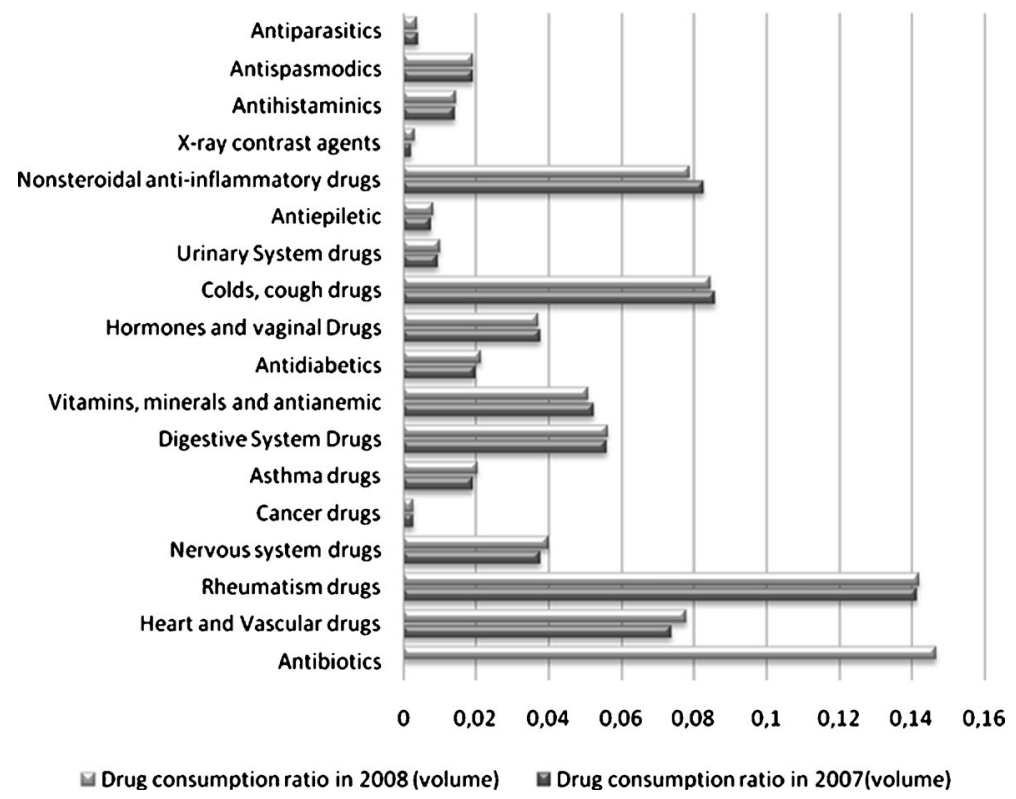

Fig. 2 Drug consumption by treatment medication category in Turkey (2007-2008) http://www.ieis.org.tr 
commonly used in medical and veterinary sciences (Metcalfe et al. 2003). It is known that $60 \%$ of the dosage is excreted from the body without being metabolized, and it is relatively persistent in the environment (Kosjek et al. 2005). A study in Turkey detected $15.58 \pm 1.5 \mathrm{ng} / \mathrm{L}$ of naproxen in surface waters (Dökmeci et al. 2013).

In Turkey, by 2008, the prescription (Rx) drug market was valued at 12 billion TRY (9.3 US dollars) annually, following a $9 \%$ growth, and box sales had reached 1.38 billion after an expansion of $5 \%$. Antibiotics rank first in box sales. As presented in Fig. 2, non-steroidal antiinflammatory drugs (NSAIDs) have the same market share as cold and flu medicines. Similarly to Turkey, over-the-counter sales of NSAIDs reach hundreds of tonnes in many other countries.

The components selected in our study are medicine groups that are frequently consumed and that are sold without a list of ingredients. The studies show that these medicine components are individually present in low concentrations in the receiving environment. However, as other components are also present in the receiving environment, the threat posed by mixture toxicity should not be ignored. All the NSAIDs utilized in our study have diverse biological effects on various cellular sources, such as vasodilatation, bronchoconstriction, natural killer activation inhibitions, suppressor $\mathrm{T}$ modulation, platelet activity inhibition, platelet aggregation and vasoconstriction (Dökmeci 2007). As a result of the disposal of these drugs, which are intended to produce specific effects in medicine or veterinary science, there will be undesirable side-effects for organisms in the receiving environment.

The individual acute toxicity alignment of ibuprofen, naproksen, diclofenac and salicylic acid, according to $\mathrm{EC}_{50}$ values, were found to be: $\mathrm{DIC}>\mathrm{IBU}>\mathrm{NAP}>\mathrm{SA}$. When diclofenac was compared with other components in acute toxicity alignment, the $\mathrm{EC}_{50}$ value $(11.79 \pm$ 1.75) was found to be very close to the $\mathrm{EC}_{50}$ value which we determined for the INDS mixture. The $\mathrm{EC}_{50}$ rate of the mixture of ibuprofen, naproxen, diclofenac and salicylic acid together was $7.09 \pm 5.1 \mathrm{mg} / \mathrm{L}$, which is classified as very toxic. These results are consistent with the findings by Cleuvers (2004), who reported in a QSAR approach-based study that NSAIDs acted on Daphnia and algae by nonpolar narcosis and that the higher the $\log K_{\text {ow }}$ of the substance, the higher was its toxicity. However, Rudzok et al. (2011) found a weak bond between toxicity and the $\log K_{o w}$ values of the organic polluters. This difference in the studies is considered to originate from the structure of the chemical substance.

\section{Conclusions}

Drug components are not toxic at their existing concentrations in the environment; however, they might become toxic as mixtures, due to what is termed the synergistic impact or total impact. It is not possible to determine the acute toxic effects of medicine mixtures in receiving environments by taking their individual effects as a basis. Our knowledge about drug residues in aquatic environments indicates that they will not solely present a risk for acute toxicity. Since these components do not exist in isolation but coexist with diverse organic and inorganic chemicals, it is necessary to monitor these drug components in wastewater discharge effluents and to optimize wastewater treatment plants. Furthermore, there are very few studies about the chronic toxicities of these chemicals on the organisms in the receiving environment. The development of these studies is very important in terms of eco-toxicology science as a whole.

Acknowledgments This study was supported by Trakya University Scientific Research Project TÜBAP-120. The authors are grateful to the TUBITAK Marmara Research Center for conducting the toxicity measurements. An initial version of this paper was presented at the 8th International Conference of the EWRA in Porto, Portugal, June 26-29, 2013. 


\section{References}

Altenburger R, Backhaus T, Boedeker W, Faust M, Scholze M, Grimme LH (2000) Predictability of the toxicity of multiple chemical mixtures to A. fischeri: mixtures composed of similarly acting chemicals. Environ Toxicol Chem 19:2341-2347

Andreozzi R, Raffaele M, Nicklas P (2003) Pharmaceuticals in STP effluents and their solar photodegradation in aquatic environment. Chemosphere 50(10):1319-1330

ASTMD 5660 (1996) Standard Test Method for Assessing the Microbial Detoxification of Chemically Contaminated Water and Soil Using a Toxicity Test with a Luminescent Marine Bacterium. American Society for Testing and Materials International 1-9

Ayscough NJ, Fawell J, Franklin G, Young W (2000) Review of human pharmaceuticals in the environment R\&D technical report. Environ Agency, Bristol

Backhaus T, Altenburger R, Boedeker W, Faust M, Scholze M, Grimme LH (2000) Predictability of the toxicity of a multiple mixture of dissimilarly acting chemicals to Vibrio fischeri. Environ Toxicol Chem 19:23482356

Buser HR, Poiger T, Müller MD (1998) Occurrence and fate of the pharmaceutical drug diclofenac in surface waters: rapid photodegradation in a lake. Environ Sci Technol 32(22):3449-3456

Castillo M, Alonso MC, Riu J, Reinke M, Klöter G, Dizer H, Fischer B, Hansen PD, Barcelo D (2001) Identification of cytotoxic compounds in European wastewaters during a field experiment. Anal Chim Acta 426:265-277

Cleuvers M (2003) Aquatic ecotoxicity of pharmaceuticals including the assessment of combination effects. Toxicol Lett 142:185-194

Cleuvers M (2004) Mixture toxicity of the anti-inflammatory drugs diclofenac, ibuprofen, naproxen, and acetylsalicylic acid. Ecotoxicol Environ Saf 59:309-315

Daughton CG, Ternes TA (1999) Pharmaceuticals and personal care products in the environment: agents of subtle change? Environ Health Perspect 107:907-938

Dietrich DR, Webb SF, Petry T (2002) Hot spot pollutants: pharmaceuticals in the environment. Toxicol Lett 131: $1-3$

Dietrich S, Ploessl F, Bracher F, Laforsch C (2010) Single and combined toxicity of pharmaceuticals at environmentally relevant concentrations in Daphnia magna-A multigenerational study. Chemosphere 79: 60-66

Dökmeci I (2007) Farmakoloji, İlaçlar ve etkileri. Alfa yayınevi, Istanbul

Dökmeci AH, Sezer K, Dökmeci İ, Ibar H (2013) Determination of selected acidic pharmaceuticals and caffeine in Ergene basin, in Turkey. Glob NEST J 15:431-439

Farré M, Ferrer I, Ginebreda A, Figueras M, Olivella L, Tirapu L, Vilanova M, Barcelo D (2001) Determination of drugs in surface water and wastewater samples by liquid chromatography-mass spectrometry: methods and preliminary results including toxicity studies with Vibrio fischeri. J Chromatogr A 938:187-197

Fatta D, Nikolaou A, Achilleos A, Meric S (2007) Analaytical methods for tracing pharmaceutical residues in water and wastewater. Trends Anal Chem 26:515-533

Faust M, Altenburger R, Backhaus T, Blanck H, Boedeker W, Gramatica P, Hamer V, Scholze M, Vighi M, Grimme LH (2001) Predicting the joint algal toxicity of multicomponent s -triazine mixtures at low-effect concentrations of individual toxicants. Aquat Toxicol 56:13-32

Ferrari B, Paxeus N, Lo Giudice R, Pollio A, Garric J (2003) Ecotoxicological impact of pharmaceuticals found in treated wastewaters: study of carbamazepine clofibric acid and diclofenac. Ecotoxicol Environ Saf 55: 359-370

Flaherty CM, Dodson SI (2005) Effects of pharmaceuticals on Daphnia survival, growth, and reproduction. Chemosphere 61:200-207

Heberer T (2002) Occurrence fate and removal of pharmaceutical residues in the aquatic environment: a review of recent research data. Toxicol Lett 131:5-17

Henschel KP, Wenzel A, Diedrich M, Fliedner A (1997) Environmental hazard assessment of pharmaceuticals. Regul Toxicol Pharmacol 25:220-225

International Standard Organisation (1998) Water-quality determination of the inhibitory effect of water samples on the light emission of Vibrio fischeri (luminescent bacteria test) EN ISO 11348-3 Geneva

Jones OA, Voulvoulis N, Lester JN (2002) Aquatic environmental assessment of the top 25 English prescription pharmaceuticals. Water Res 36:5013-5022

Karl F, Anna WA, Daniel C (2005) Ecotoxicology of human pharmaceuticals: a review. Aquat Toxicol 76:122159

Kosjek T, Heath E, Krbavcic A (2005) Determination of non-steroidal anti-inflammatory drug (NSAIDs) residues in water samples. Environ Int 31:679-685 
Koutsouba V, Heberer T, Fuhrmann B, Schmidt-Baumler K, Tsipi D, Hiskia A (2003) Determination of polar pharmaceuticals in sewage water of Greece by gas chromatography-mass spectrometry. Chemosphere 51: 69-75

Lang J, Kohidai L (2012) Effects of the aquatic contaminant human pharmaceuticals and their mixtures on the proliferation and migratory responses of the bioindicator freshwater ciliate Tetrahymena. Chemosphere 89: 592-601

McCarty LS, MacKay D (1993) Enhancing ecotoxicological modelling and assessment. Environ Sci Technol 27: $1719-1728$

Metcalfe CD, Miao XS, Koenig BG, Struger J (2003) Distribution of acidic and neutral drugs in surface waters near sewage treatment plants in the lower Great Lakes Canada. Environ Toxicol Chem 22:2881-2889

Onorati F, Mecozzi M (2003) Effects of two diluents in the Microtox toxicity bioassay with marine sediments. Chemosphere 54:679-687

Parvez S, Venkataraman C, Mukherji S (2006) A review on advantages of implementing luminesence inhibition test (Vibrio fischeri) for acute toxicity prediction of chemicals. Environ Int 32:256-268

Ra JS, Oh SY, Lee BC, Kim SD (2008) The effect of suspended particles coated by humic acid on the toxicity of pharmaceuticals estrogens and phenolic compounds. Environ Int 34:184-192

Radix P, Leonard M, Papantoniou C, Roman G, Saouter E, Gallotti-Schmitt S, Thiebaund H, Vasseur P (2000) Comparison of four chronic toxicity tests using algae, bacteria and intertebrates assessed with sixteen chemicals. Ecotoxicol Environ Saf 47:186-194

Ren S, Frymier PD (2002) Estimating the toxicities of organic chemicals to bioluminesencent bacteria and activated sludge. Water Res 36:4406-4414

Rodriguez I, Quintana JB, Carpinteiro J, Carro AM, Lorenzo RA, Cela R (2003) Determination of acidic drugs in sewage water by GC-MS as tert-butyldimethylsilyl derivatives. J Chromatogr A 985:265-274

Rudzok S, Krejci S, Graebsch C, Herbarth O, Mueller A, Bauer M (2011) Toxicity profiles of four metals and 17 xenobiotics in the human hepatoma cell line HepG2 and the protozoa Tetrahymena pyriformis - a comparison. Environ Toxicol 26:171-186

Sanderson H, Johnson DJ, Wilson CJ, Brain RA, Solomon KR (2003) Probabilistic hazard assessment of environmentally occurring pharmaceuticals toxicity to fish, daphnids and algae by ECOSAR screening. Toxicol Lett 144:383-395

Schnell S, Bols NC, Barata C, Porte C (2009) Single and combined toxicity of pharmaceuticals and personal care products (PPCPs) on the rainbow trout liver cell line RTL-W1. Aquat Toxicol 93:244-252

Sprague JB, Ramsay BA (1965) Lethal levels of mixed copper-zinc solutions for juvenile salmon. J Fish Res Board Can 22:425-432

Ternes T, Hirsch R, Mueller J, Haberer K (1998) Methods for the determination of neutral drugs as well as beta blockers and alpha2-sympathomimetics in aqueous matrices using GC/MS and LC/MS/MS. Fresenius J Anal Chem 362:329-340

Wiegel S, Aulinger A, Brockmeyer R, Harms H, Loffler J, Reincke H, Schmidt R, Stachel B, Von TW, Wanke A (2004) Pharmaceuticals in the river Elbe and its tributaries. Chemosphere 57:107-126

Zhang XJ, Qin HW, Su LM, Qin WC, Zou MY, Sheng LX, Zhao YH, Abraham MH (2010) Interspecies correlations of toxicity to eight aquatic organisms: theoretical considerations. Sci Total Environ 408:45494555 